\title{
Assessment of Competencies' Level of Critical and Intensive Care Unites Nurses at King Abdulaziz Medical City and King Abdullah Specialized Children Hospital
}

\author{
Bothyna Zakaria Murshid \\ Medical \& Surgical Nursing Department, College of Nursing, King Saud Bin Abdul-Aziz University for Health Sciences, Riyadh, Kingdom \\ of Saudi Arabia
}

Email address:

murshidb@ksau-hs.edu.sa

To cite this article:

Bothyna Zakaria Murshid. Assessment of Competencies' Level of Critical and Intensive Care Unites Nurses at King Abdulaziz Medical City and King Abdullah Specialized Children Hospital. American Journal of Nursing Science. Vol. 10, No. 1, 2021, pp. 28-35.

doi: 10.11648/j.ajns.20211001.16

Received: December 24, 2020; Accepted: January 12, 2021; Published: January 22, 2021

\begin{abstract}
Critical Care Nursing reflects a holistic approach in caring of patients, critical care nurses are registered nurses who are trained and skilled to practice critical care nursing for critically ill patients, she carries out independent interventions and collaborates patient care activities to address life-threatening situations that will meet patient's physical, psychological, cultural and spiritual needs. The aim of the study was to explore competence levels of intensive care unit nurses and related socio demographic characteristics. Setting: the study was conducted at all Intensive and Critical Care Units, King Abdulaziz Medical City and King Abdullah Specialized Children Hospital. Sample: Representative convenient sample of 233 intensive and critical care unit nurses were included in the study. Tools: Intensive and Critical Care Nursing Competence Scale (ICCNCS-1) was used for the purpose of the study, it is a self-assessment questionnaire consisting of two main basic competence; clinical competence and professional competence with a total of 140 items; each basic competence comprises four essential sub domains; knowledge, skills, attitude and value and experience base. Results of the study revealed that majority of the studied nurses has excellent total level of competency, with highest percent of the studied nurses who have good competency level related to knowledge base and there was a significant difference between total competency level of the studied nurses and their working unit and years of experience in the current Unit. Recommendation: Adding of more than one data collection method to avoid subjectivity of self-assessment scale results.
\end{abstract}

Keywords: Competencies' Level, Critical Care Unites, Intensive Care Units

\section{Introduction}

Intensive care unit (ICU) and Critical care unit (CCU) considered as one of the most critically functioning operational environments in a hospital, patients admitted to these units may have an emergency admission with critical and life-threatening health status, following surgery, unexpected admission post-accident or be transferred from other wards because of unexpected deterioration in their health. Critical care nursing is a unique nursing specialty whereas advanced technology is incorporated with physical and psychosocial challenges and ethical conflicts associated while caring of critically ill patients [13]. Every ICU and CCU in a hospital have a different environment that reflects the specialist medical and surgical procedures they perform. Most ICUs are fairly large sterile areas with a high attention of specialized, technical, and monitoring equipment needed to care for critically ill patients. The framework of critical care nursing is a complex and challenging area of nursing practice [25].

Close observation, continuous assessment and monitoring are required for seriously ill patients who are usually admitted to ICUs and CCUs [15]. Nurses who are working in these units need sufficient knowledge, good skills, and special training to be able to provide care for critically ill patients [14]. Patients admitted to ICU and CCU may need special equipment, instruments, machines, and apparatus in their room depending on their medical situation and 
diagnosis, this required equipment may seem overwhelming [5]. Patients usually will be connected to machines such as mechanical ventilator to help them breathing or to monitor to assess their vital signs such as their blood pressure, heart, and respiratory rate or pulse oximetry to check their arterial blood oxygen saturation (Yoon, 2018). Working with these machines or equipment in such units is a complex combination of knowledge, skills, practice, attitudes, and values [15].

ICU and CCU nurses are registered nurses who are specialize in providing direct care to patients in life threatening situations in all ages within intensive care units of hospitals [20]. Lifetime learning and the spirit of investigation are essential for the critical care nurse to enhance and maintain their competencies and to advance nursing practice; the ICU and CCU nurse's ability to make sound clinical nursing judgments is based on a concrete basis of knowledge and skills [10].

Competence is defined as knowledge and performance combined with psychomotor and clinical problem-solving skills and a responsive attitude [6]. General competence involves an adequacy of performance and the ability to combine knowledge and skills around attitudes, values, and practices [16]. Nurses' competencies are statements that describing behaviors that nurses believe are important to provide safe, effective, and ethical patient care, in addition; nurses competencies have been designed to provide nursing staff with the core skills required to take charge in ICU and $\mathrm{CCU}$; construction management and leadership ability into professional development, to demonstrate safe and effective coordination and prioritization of unit workload, workforce and resources [22]. Competencies of critical care nurses are crucial and developed to achieve nurses' roles in practice, management, leadership, and research. Competent ICU and $\mathrm{CCU}$ nurses have a direct and significant short- and long-term impact on ICU patients' physiological and psychological outcomes, as evidence-based nursing interventions and ethical activity [19].

At the basis of increase in global demand for competent critical care services, vast advanced technology, important changes in response to the needs of individuals' health and to improve the quality of the health service; there is an increase of the nurses' knowledge, competencies, and responsibilities [2]. Nowadays, critical care is mostly delivered in intensive care units (ICUs) which are highly specialized and considered as one of the vital and essential departments in the hospital which provides the highest level of care to the patients in severe or life-threatening conditions by specially trained staff [12]. Therefore, Care in the ICUs and CCUs is unique, incredibly special and differs from other hospital units [5].

The Critical Care Nurse may also work in collaboration with the operating theatre nurse in post anesthetics and recovery care unit though complex respiratory and hemodynamic compromise can be accommodated by direct transfer of the critically ill patient to ICU hence the location of the operating theatre is close to the ICU especially the cardiothoracic ICU [24]. Competences of nurses are a complex combination of four domains, which are knowledge, skills, attitudes and values, and experience base [16]. Delivering care for patients in Critical and Intensive Care Units are require nurses' competences. Self-assessment is an essential ability that can be learned and developed during education and nursing career [19].

Hence the aim of the present study is to assess competencies' level of critical and intensive care units' nurses.

\subsection{Aim of the Study}

This study aimed to explore competence levels of intensive care unit nurses and related socio demographic characteristics at King Abdul-Aziz Medical City (KAMC) and Abdul-Aziz Specialized Children Hospital (KASCH).

\subsection{Research Questions}

1. What is the overall competence level of intensive and critical care unit nurses?

2. What is the association between nurses' characteristics and their level of competence?

\section{Materials and Methods Setting}

There are approximately 14 Critical and Intensive Care Units at King Abdulaziz Medical City and King Abdullah Specialized Children Hospital, Riyadh, King of Saudi Arabia. The study was conducted at all intensive and critical care units which are affiliated to the Ministry of National Guard Health Affairs as follow: Intensive care Unit (ICU), Intensive Care Unit 2 (ICU2), Intensive Care Unit 10 (ICU10), Critical Care Unit (CCU), Neonatal Intensive Care Unit (NICU), Surgical Intensive Care Unit (SICU), Burn Intensive Care Unit BICU), Neurology Critical Care Unit (NCCU), Intermediate Medical Care Unit (IMCU), Trauma Intensive Care Unit (TICU), Progressive Care Unit (PCU), Medical Cardiac Intensive Care Unit (MCICU), Adult Cardiac Intensive Care Unit (ACICU), and Pediatric Cardiac Intensive Care Unit (PCICU).

\subsection{Materials}

\subsubsection{Study Subjects}

Representative convenient sample of nurses who are working in ICU and CCU and agree to participate in the study (233 nurses) were included in the present study with the following criteria.

\subsubsection{Inclusion Criteria}

Nurses who have at least two years of experience in any

Intensive or critical care unites.

Nurses who can read write and speak English.

\subsubsection{Study Design}

The study utilized a descriptive survey design.

\subsubsection{Sample Size}

There are 591 nurses are working at different Intensive and 
Critical Care Unites at KAMC and $\mathrm{KASCH}$. A representative sample of 233 nurses was included in the study as it was calculated by using power analysis with confidence level of $95 \%$ with $5 \%$ margin of error.

\subsubsection{Sampling Technique}

Randomization was used to select the representative sample of the study subjects from all different ICU and CCU at $\mathrm{KAMC}$ and $\mathrm{KASCH}$.

\subsubsection{Tools of the Study}

A Self-assessment questionnaire was used for the purpose of data collection. The questionnaire is comprises two main parts as follow:

Part I: Nurses Socio-demographic characteristics: Sociodemographic data elicited from Nurses included age, gender, job title, nationality, working unit, education level, total years of experience, years of experience in the current unit and mother tongue language.

Part II: The Intensive and Critical Care Nursing Competence Scale version 1 (ICCN-CS-1):

This part was developed by Lakanmaa R., 2013 and adopted by the researchers to assess Intensive and Critical Care Nurses' Competence level; the scale is a selfassessment tool which constitute two main basic competence; clinical competence (80 Items) and professional competence (64 Items) with total of 144 items, furthermore; each of the two main parts is subdivided into four sub domains as follow (knowledge, skills, attitude and values, and experience base) where Each sub domain comprises 36 items. Each item will be scaled on a 5 point Likert scale score, For knowledge domain; nurses responses were scaled as; very poor (1), poor (2), Nether poorly nor well (3), well (4), very well (5), as for skills, attitude and values; nurses responses were scaled as; Fully disagree (1), disagree (2), Nether disagree nor agree (3), agree (4), Fully agree (5), and as related to experience, nurses responses were scaled as Very poorly (1), Poorly (2), Nether poorly nor well (3), well (4), Very well (5). Total score can be ranged from 144-720, the total marks will be summed up and the total competence level will be estimated as: Moderate Competency (289-432), Good Competency (433576), Excellent Competency, (577-720). The reported validity and ratability were found to be 0.98 and $80 \%$ respectively by using Cronbach's Alpha.

\subsection{Method of Data Collection}

1. An official Permission to carry out the study was obtained from research unit; Collage of Nursing, Riyadh, nursing education center and King Abdulla International Medical research center (KAIMRC), Riyadh, King of Saudi Arabia.

2. Nurses' written consent to participate in the study was obtained after explaining the purpose of the study and the right to withdraw at any time of the study.

3. Nurses' confidentiality was ascertained of all participants at all time of the study period.
4. Each Questionnaire was given a code, so no participant identification was required.

5. The self-assessment questionnaire was distributed to all nurses included in the study in different ICU and CCU at $\mathrm{KAMC}$ and $\mathrm{KASCH}$ with individual explanation of the study purpose, questionnaire items and scoring system.

6. After one week, the questionnaire was collected from nurses included in the study.

7. Data was collected over a period of 8 weeks starting from March to April 2018.

8. The questionnaire was used to assess ICU and CCU nurses' level of competency.

\subsection{Data Analysis}

Data was coded and the analysis of the data was performed using statistical software SPSS version.

Means, stander deviation, medians, number, and percentage were calculated. Chi square was used as a test of significance, as $\mathrm{P}=0.05$.

\section{Results}

Table 1 demonstrated distribution of the studied nurses regarding their socio-demographic characteristics; it showed that the highest percent $42.5 \%$ of nurses' age ranging from $31-40$ years while only small percent of them $4.7 \%$ and $9.4 \%$ aged 20-45 and $\geq 46$ years, respectively. Majority of nurses $(87.6 \%)$ were females, highest percent of the studied nurses (40.8\%) are Philippine, followed by $30 \%$ Malaysian, small and equal percent $5.2 \%$ South African and Indian, while about tenth $9.9 \%$ of the participant are Saudi and $6 \%$ of them have other nationalities.

Same Table revealed that most of the studied nurses $87.1 \%$ are registered nurses, while small percent $4.7 \%$, $1.3 \%$ and $2.1 \%$ of them are nurse manger, certified registered nurse, and preceptor, respectively. In addition, more than half $64.4 \%$ have bachelor on nursing degree (BSN) and about quarter $25.8 \%$ have nursing diploma while small percent (9\%) have master's degree of nursing. In relation to nurse' total years of experience; it was found that less than half $(42.1 \%)$ of the nurses have from 6-10 years of total experience while about tenth of them $(10.3 \%)$ have $\geq 21$ years of experience and less than fifth of them $16.3 \%, 19.3 \%$ and $12 \%$ have from $1-5$, 11-15 and 16-20 years of experience, respectively. Regarding to years of experience in the current ICUs \& CCUs; results proved that the highest percent of the studied nurse $(41.6 \%)$ are working in their current units from 1-3 yeas followed by 30.5\% who have 4-6 years of experience while small and equal percent $(3.9 \%)$ have 10-12 and 13-15 years of experience.

Moreover, same table illustrated that highest percent of the studied nurses $15 \%$ working in ICUs, followed by $10.7 \%$ and $9.4 \%$ who are working in neonates critical care unit and medical care intensive care unit, respectively. 
Table 1. Distribution of the studied nurses regarding their sociodemographic characteristics.

\begin{tabular}{|c|c|c|}
\hline \multirow{2}{*}{ Characteristics } & \multicolumn{2}{|c|}{ The studied nurses $(n=233)$} \\
\hline & $\mathbf{N}$ & $\%$ \\
\hline \multicolumn{3}{|l|}{ Age (in years) } \\
\hline $20-25$ & 11 & 4.7 \\
\hline $26-30$ & 73 & 31.3 \\
\hline $31-40$ & 99 & 42.5 \\
\hline $41-45$ & 28 & 12.0 \\
\hline$\geq 46$ & 22 & 9.4 \\
\hline \multicolumn{3}{|l|}{ Gender } \\
\hline Female & 204 & 87.6 \\
\hline Male & 29 & 12.4 \\
\hline \multicolumn{3}{|l|}{ Nationality } \\
\hline Saudi & 23 & 9.9 \\
\hline Jordanian & 6 & 2.6 \\
\hline Malaysian & 70 & 30.0 \\
\hline Pilipino & 95 & 40.8 \\
\hline Indian & 12 & 5.2 \\
\hline South African & 12 & 5.2 \\
\hline Australian & 1 & 0.4 \\
\hline Other Nationality & 14 & 6.0 \\
\hline \multicolumn{3}{|l|}{ Job title } \\
\hline Nurse Manger & 11 & 4.7 \\
\hline Nurse Supervisor & 2 & 0.9 \\
\hline Certified Registered Nurse (CRN) & 3 & 1.3 \\
\hline Preceptor & 5 & 2.1 \\
\hline Registered Nurse & 203 & 87.1 \\
\hline Other & 9 & 3.9 \\
\hline \multicolumn{3}{|l|}{ Working unit } \\
\hline ICU & 35 & 15.0 \\
\hline $\mathrm{CCU}$ & 15 & 6.4 \\
\hline NICU & 2 & 0.9 \\
\hline SICU & 23 & 9.9 \\
\hline $\mathrm{BICU}$ & 16 & 6.9 \\
\hline $\mathrm{NCCU}$ & 25 & 10.7 \\
\hline ICU2 & 12 & 5.2 \\
\hline IMCU & 3 & 1.3 \\
\hline TICU & 17 & 7.3 \\
\hline PCU & 11 & 4.7 \\
\hline MCICU & 22 & 9.4 \\
\hline $\mathrm{ACICU}$ & 14 & 6.0 \\
\hline PCICU & 18 & 7.7 \\
\hline ICU10 & 20 & 8.6 \\
\hline \multicolumn{3}{|l|}{ Level of education } \\
\hline Master & 21 & 9.0 \\
\hline BSN & 150 & 64.4 \\
\hline Diploma & 60 & 25.8 \\
\hline Other & 2 & 0.9 \\
\hline \multicolumn{3}{|l|}{ Total years of experience } \\
\hline $1-5$ & 38 & 16.3 \\
\hline 6-10 & 98 & 42.1 \\
\hline $11-15$ & 45 & 19.3 \\
\hline $16-20$ & 28 & 12.0 \\
\hline$\geq 21$ & 24 & 10.3 \\
\hline \multicolumn{3}{|c|}{ Years of Experience in the current Unit } \\
\hline $1-3$ & 97 & 41.6 \\
\hline $4-6$ & 71 & 30.5 \\
\hline $7-9$ & 35 & 15.0 \\
\hline $10-12$ & 9 & 3.9 \\
\hline $13-15$ & 9 & 3.9 \\
\hline $16-18$ & 3 & 1.3 \\
\hline $19-21$ & 3 & 1.3 \\
\hline$\geq 22$ & 6 & 2.6 \\
\hline
\end{tabular}

Table 2 illustrated total mean scores of competency domains of the studied nurses. It showed that; nurses' responses in all sub domains of competency were ranging from the minimum to the maximum scores (36-180) of each sub domains with the highest mean and standard deviation of attitude and value domain (164.61 \pm 23.344$)$ followed by (162.10 \pm 18.086$)$ for knowledge domain, moreover the total competency score of all domains ranged from (144-720) with mean and standard deviation of (648.06 \pm 79.797$)$. Total mean scores of competency domains are illustrated in figure 1.

Table 2. Total mean scores of competency domains of the studied nurses.

\begin{tabular}{lll}
\hline Total competency domains scores & Range & Mean \pm SD \\
\hline 1. Total knowledge score & $(36-180)$ & $162.10 \pm 18.086$ \\
2. Total skills score & $(36-180)$ & $160.71 \pm 23.316$ \\
3. Total attitude and value score & $(36-180)$ & $164.61 \pm 23.344$ \\
4. Total experience score & $(36-180)$ & $160.64 \pm 24.097$ \\
Total competency score & $(144-720)$ & $648.06 \pm 79.797$ \\
\hline
\end{tabular}

Table 3 presented distribution of the studied nurses regarding to sub domain of competency levels; it revealed that highest percent of the studied nurses' $76.8 \%$ have good competency level related to knowledge base followed by $75.1 \%$ for attitude and value bas and $71.7 \%, 70.4 \%$ for skills and experience base, respectively.

Table 3. Distribution of the studied nurses regarding to sub domains competency levels.

\begin{tabular}{llllllll}
\hline \multirow{2}{*}{$\begin{array}{l}\text { Total competency domains } \\
\text { levels }\end{array}$} & \multicolumn{3}{l}{ The studied nurses $(\mathbf{n = 2 3 3 )}$} \\
\cline { 2 - 8 } & \multicolumn{2}{l}{ Poor } & \multicolumn{3}{l}{ Fair } & \multicolumn{3}{c}{ Good } \\
\cline { 2 - 7 } & $\mathbf{N}$ & $\mathbf{\%}$ & $\mathbf{N}$ & $\mathbf{\%}$ & $\mathbf{N}$ & $\mathbf{\%}$ \\
\hline 1. Total knowledge level & 3 & 1.3 & 51 & 21.9 & 179 & 76.8 \\
2. Total skills level & 7 & 3.0 & 59 & 25.3 & 167 & 71.7 \\
3. Total attitude and value level & 5 & 2.1 & 53 & 22.7 & 175 & 75.1 \\
4. Total experience level & 6 & 2.6 & 63 & 27.0 & 164 & 70.4 \\
\hline
\end{tabular}

$<60 \%$ Poor $(60-75) \%$ Fair $>75 \%$ Good

On the other hand, it was found that more than fourth of the studied nurses $27.0 \%$ have fair competency level related to experience base followed by $25.3 \%, 22.7 \% \& 21.9 \%$ of the nurses who have fair level related to skills, attitude and value and knowledge, respectively. In addition, same table proved that small percent of the studied nurses have poor competency level related to knowledge, skills, attitude and value and experience base $1.3 \%, 3.0 \%, 2.1 \%$ and $2.6 \%$ respectively as shown in figure 2 .

Table 4. Distribution of the studied nurses regarding their total competency level.

\begin{tabular}{lll}
\hline \multirow{2}{*}{ Total competency level } & \multicolumn{2}{l}{ The studied nurses $(\mathbf{n}=\mathbf{2 3 3})$} \\
\cline { 2 - 3 } & $\mathbf{N}$ & $\mathbf{\%}$ \\
\hline (144-288) Poor competency. & 3 & 1.3 \\
(89-432) Moderate competency. & 1 & 0.4 \\
$(433-576)$ Good competency. & 32 & 13.7 \\
(577-720) Excellent competency. & 197 & 84.5 \\
\hline
\end{tabular}

Table 4 represents distribution of the studied nurses regarding their total competency level; this table showed that majority of the studied nurses $84.5 \%$ has excellent total level of competency, less than fifth $13.7 \%$ have good competency, and small percent $0.4 \%, 1.3 \%$ have moderate and poor total competency level respectively as illustrated in figure 3 . 
Table 5 illustrated comparison between socio-demographic characteristics of the studied nurses and their total competency level; it showed that highest and same percent of nurses who have excellent competency level $35.2 \%$ aged from 31-40 years, and are Philopino, while more than half $55.4 \%$ of them are BSN holder, 35.6\% have from 6-10 total years of nursing experience and $34.8 \%$ of them have from 1-3 years of experience working in their current ICUs and CCUs units. Also, it was found that there was a significant difference between total competency level of the studied nurses and their working unit and years of experience in the current unit since $\mathrm{P}$ value $\equiv 0.00$ and 0.026 , respectively.

Table 5. Comparison between socio-demographic characteristics of the studied nurses and their total competency level.

\begin{tabular}{|c|c|c|c|c|c|c|c|c|c|}
\hline \multirow{3}{*}{ Characteristics } & \multicolumn{8}{|c|}{ The studied nurses $(n=233)$ Total competency level } & \multirow{3}{*}{$\chi 2 \mathrm{P}$} \\
\hline & \multicolumn{2}{|c|}{ Poor Competency $(n=3)$} & \multicolumn{2}{|c|}{ Fair Competency $(n=1)$} & \multicolumn{2}{|c|}{ Good Competency $(n=32)$} & \multicolumn{2}{|c|}{ Excellent Competency $(n=197)$} & \\
\hline & $\mathbf{N}$ & $\%$ & $\mathbf{N}$ & $\%$ & $\mathbf{N}$ & $\%$ & $\mathbf{N}$ & $\%$ & \\
\hline \multicolumn{10}{|l|}{ Age (in years) } \\
\hline $20-25$ & 0 & 0.0 & 0 & 0.0 & 3 & 1.3 & 8 & 3.4 & \\
\hline $26-30$ & 0 & 0.0 & 0 & 0.0 & 13 & 5.6 & 60 & 25.8 & 10.831 \\
\hline $31-40$ & 3 & 1.3 & 1 & 0.4 & 13 & 5.6 & 82 & 35.2 & 0.543 \\
\hline $41-45$ & 0 & 0.0 & 0 & 0.0 & 2 & 0.9 & 26 & 11.2 & \\
\hline$\geq 46$ & 0 & 0.0 & 0 & 0.0 & 1 & 0.4 & 21 & 9.0 & \\
\hline \multicolumn{10}{|l|}{ Nationality } \\
\hline Saudi & 0 & 0.0 & 0 & 0.0 & 3 & 1.3 & 20 & 8.6 & \\
\hline Jordanian & 0 & 0.0 & 0 & 0.0 & 1 & 0.4 & 5 & 2.1 & \\
\hline Malaysian & 2 & 0.9 & 1 & 0.4 & 10 & 4.3 & 57 & 24.5 & \\
\hline Philippine & 1 & 0.4 & 0 & 0.0 & 12 & 5.2 & 82 & 35.2 & 11.535 \\
\hline Indian & 0 & 0.0 & 0 & 0.0 & 2 & 0.9 & 10 & 4.3 & 0.951 \\
\hline Australian & 0 & 0.0 & 0 & 0.0 & 1 & 0.4 & 0 & 0.0 & \\
\hline Others & 0 & 0.0 & 0 & 0.0 & 2 & 0.9 & 12 & 5.2 & \\
\hline \multicolumn{10}{|l|}{ Working unit } \\
\hline ICU & 0 & 0.0 & 0 & 0.0 & 5 & 2.1 & 30 & 12.9 & \\
\hline $\mathrm{CCU}$ & 3 & 1.3 & 0 & 0.0 & 4 & 1.7 & 8 & 3.4 & \\
\hline NICU & 0 & 0.0 & 0 & 0.0 & 1 & 0.4 & 1 & 0.4 & \\
\hline SICU & 0 & 0.0 & 0 & 0.0 & 2 & 0.9 & 21 & 9.0 & \\
\hline $\mathrm{BICU}$ & 0 & 0.0 & 0 & 0.0 & 1 & 0.4 & 15 & 6.4 & \\
\hline NCCU & 0 & 0.0 & 0 & 0.0 & 6 & 2.6 & 19 & 8.2 & \\
\hline ICU2 & 0 & 0.0 & 0 & 0.0 & 0 & 0.0 & 12 & 5.2 & 77.598 \\
\hline IMCU & 0 & 0.0 & 0 & 0.0 & 1 & 0.4 & 2 & 0.9 & $0.000 *$ \\
\hline TICU & 0 & 0.0 & 0 & 0.0 & 4 & 1.7 & 13 & 5.6 & \\
\hline PCU & 0 & 0.0 & 0 & 0.0 & 3 & 1.3 & 8 & 3.4 & \\
\hline MCICU & 0 & 0.0 & 0 & 0.0 & 4 & 1.7 & 18 & 7.7 & \\
\hline ACICU & 0 & 0.0 & 0 & 0.0 & 0 & 0.0 & 14 & 6.0 & \\
\hline \multicolumn{10}{|l|}{ Level of education } \\
\hline Master & 0 & 0.0 & 0 & 0.0 & 3 & 1.3 & 18 & 7.7 & \\
\hline BSN & 3 & 1.3 & 0 & 0.0 & 18 & 7.7 & 129 & 55.4 & 6.319 \\
\hline Diploma & 0 & 0.0 & 1 & 0.4 & 11 & 4.7 & 48 & 20.6 & 0.708 \\
\hline other & 0 & 0.0 & 0 & 0.0 & 0 & 0.0 & 2 & 0.9 & \\
\hline \multicolumn{10}{|l|}{ Total Years of experience } \\
\hline $1-5$ & 1 & 0.4 & 0 & 0.0 & 7 & 3.0 & 30 & 12.9 & \\
\hline $6-10$ & 0 & 0.0 & 0 & 0.0 & 15 & 6.4 & 83 & 35.6 & \\
\hline $11-15$ & 2 & 0.9 & 1 & 0.4 & 5 & 2.1 & 37 & 15.9 & 12.219 \\
\hline $16-20$ & 0 & 0.0 & 0 & 0.0 & 3 & 1.3 & 25 & 10.7 & 0.428 \\
\hline$\geq 21$ & 0 & 0.0 & 0 & 0.0 & 2 & 0.9 & 22 & 9.4 & \\
\hline Years of Experience in ICU & & & & & & & & & 35.372 \\
\hline $1-3$ & 1 & 0.4 & 0 & 0.0 & 15 & 6.4 & 81 & 34.8 & $0.026^{*}$ \\
\hline $4-6$ & 2 & 0.9 & 0 & 0.0 & 14 & 6.0 & 55 & 23.6 & \\
\hline $7-9$ & 0 & 0.0 & 0 & 0.0 & 2 & 0.9 & 33 & 14.2 & \\
\hline $10-12$ & 0 & 0.0 & 1 & 0.4 & 0 & 0.0 & 8 & 3.4 & 35.372 \\
\hline $13-15$ & 0 & 0.0 & 0 & 0.0 & 0 & 0.0 & 9 & 3.9 & $0.026^{*}$ \\
\hline $16-18$ & 0 & 0.0 & 0 & 0.0 & 0 & 0.0 & 3 & 1.3 & \\
\hline $19-21$ & 0 & 0.0 & 0 & 0.0 & 0 & 0.0 & 3 & 1.3 & \\
\hline$\geq 22$ & 0 & 0.0 & 0 & 0.0 & 1 & 0.4 & 5 & 2.1 & \\
\hline
\end{tabular}

* Significant at level $\mathrm{P}<0.005$ 


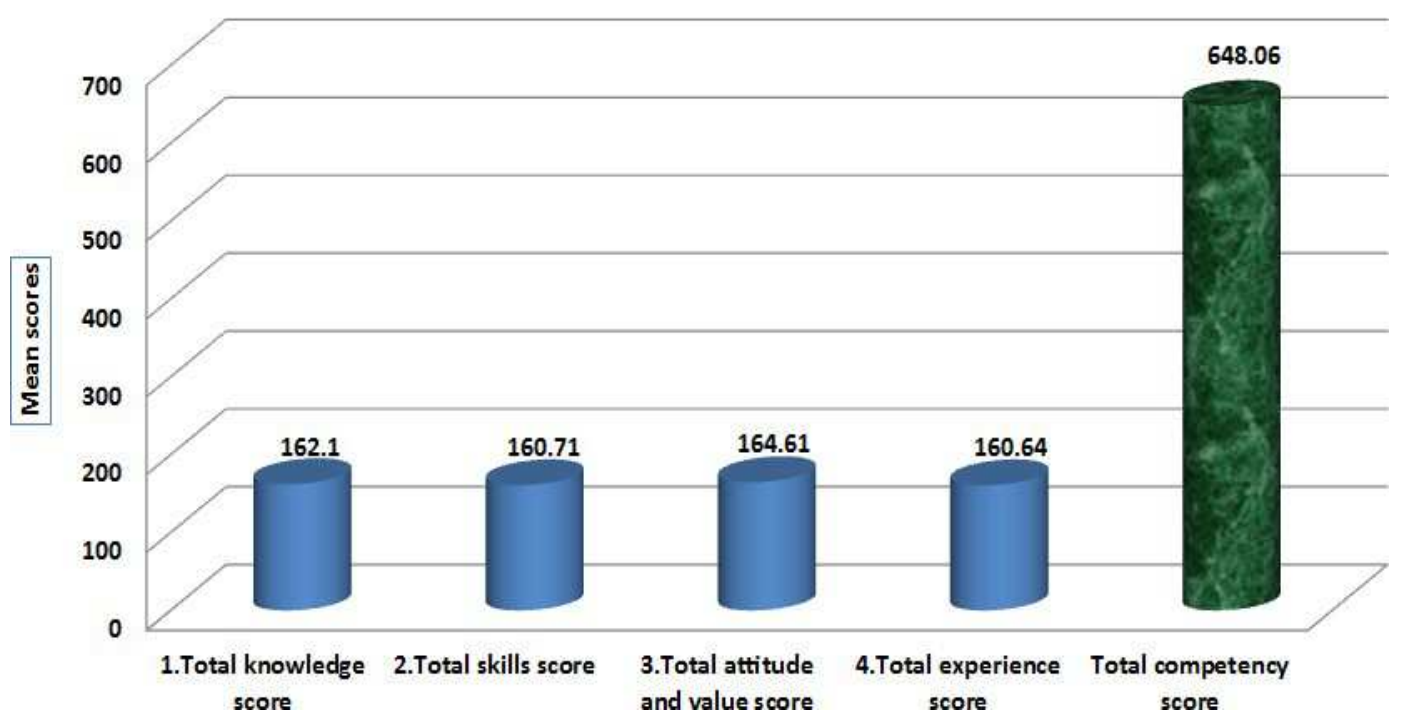

Figure 1. Total mean scores of competency domains of the studied nurses.

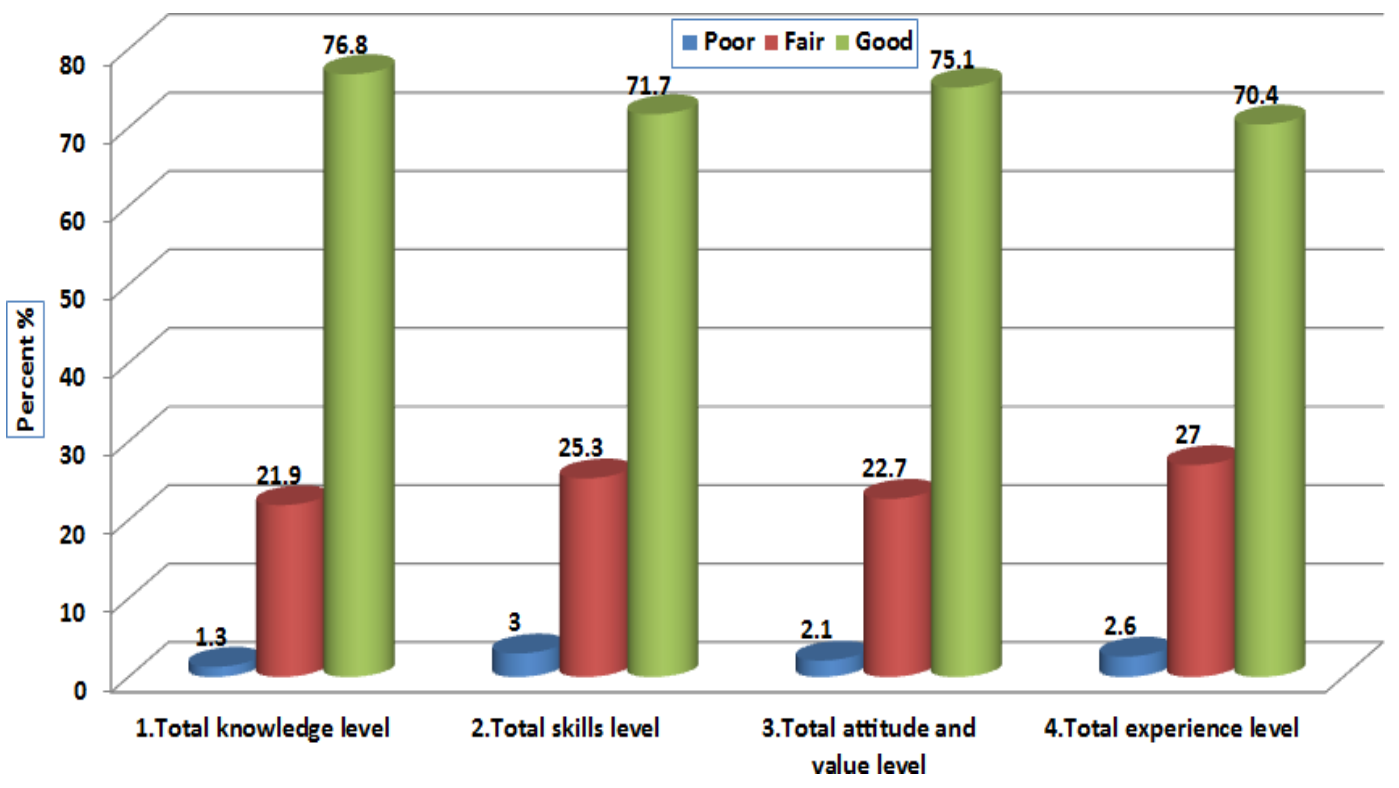

Figure 2. Distribution of the studied nurses regarding sub domains competency levels.

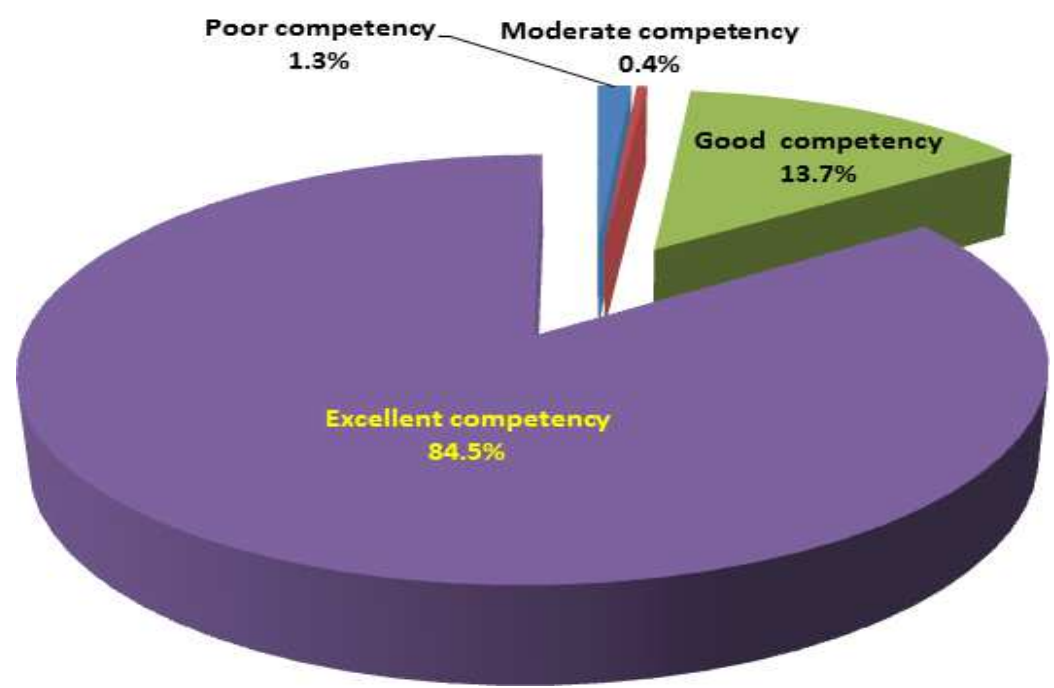

Figure 3. Distribution of the studied nurses regarding their total competency level. 


\section{Discussion}

Competence assessment in ICCN and CCU education and practice is crucial for the nurses' professional development and patient safety, The American Joint Commission on Accreditation of Healthcare Organization (AJCAHO) has declared that in order to provide quality patient care, health care professionals including nurses delivering patient care services must be competent in their knowledge and practice [1].

The age of the highest percent of the studied nurses in the percent study was ranging from 31-40 years, with 6-10 years of experience in nursing and 4-6 years of experience working in ICUs \& CCUs, majority were females, registered nurses as job title and working in different ICUs \& CCUs and Bachelor of Nursing Science holders. Lakanmaa R., 2013, stated that most participants were female, with a mean age was of 28 years, and completed high secondary school, with 3-7 years of work experience in nursing [14]. Another study done by Aqtash., S 2017, mentioned that nurses were professionally qualified, with the majority holding a bachelor's degree in nursing [3].

Regarding to subdomains of competency scale, the result of the present study documented that; studied nurses have relatively equal mean of knowledge, skills, attitude, and value and experience base scores, in addition; majority of the studied nurses reported good competency level in the four subdomains with about fourth and small percent of them who have moderate and poor competency scale scores respectively with the lowest percent of scale scores in experience base of competency.

Similar study by Alfieri 2017, represented that the students' self-rated basic competence was good, and students' attitude and value base was excellent, adding that all participants were satisfied about competences and skills in the administration and organization of the job [2]. Furthermore, Lakanmaa R., 2013 supported the present study and reported that the study subjects evaluate moderate level of knowledge and skill base and rated skill base as slightly poorer than their knowledge base [14].

Another study done by Lakanmaa R, 2015 agreed with the present one and stated that intensive care unit nurses' selfassessed basic competence was good, the attitude and value level of competence was excellent whereas experience base was the poorest compared to the knowledge and skill base of intensive and critical care nursing [15], adding that that nurses self-rated their knowledge, skill, and experience base as good, while Ghahrisarabi A., et al 2016, contradicting this result and proved that nurses had more competence in attitude and value base and the least competence level was related to knowledge [8], in addition; Jafari Z., et al. 2008, stated that novice nurses' clinical competence was in a primary level [11].

Severely ill patients admitted to ICUs and CCUs and their families benefit from the consideration of well trained and high skilled personnel; ICUs and CCUs nurses contribute to patient safety, improved patient outcomes, reduced morbidity and mortality, and reduced complications, prevent errors, and decrease overall costs. The present study illustrated that majority of ICUs and CCUs nurses included in the study have excellent total competency level, little more than tenth have good level with small percent who self-reported moderate and poor level of competency which may explained that highly technical and clinical skill is required for nurses working in the ICUs, in addition all expatriate nurses who are included in the present study underwent extensive testing as part of the recruitment strategies and job application requirement. Aqtash S., 2017 was in line and found that the studied nurses have a higher overall self-assessed level of competence score than found in most previous studies, Meretoja R., 2004 was in agreement and found that ICU nurses self-assessed their attitude and value base as excellent.

Other studies done by O'Leary J., 2012 and Meretoja R., 2015 stated that clinical competence, was rated as high while professional competence was rated as low which can be attributed to the fact that ICU nurses are more accustomed with safe and direct patient-centered care than with adherence to ethical codes and general health care rules and regulation [21, 17].

The related factors of competency level of the present study were age, gender, nationality, job title, level of education, working units, years of work experience in nursing and years of experience in ICUs and CCUs. The result of the present study showed that working units and number of years of experience in the current units was significant factors related to competency level of ICUs and CCUs nurses; a study was done by Bahreini M., et al. 2010 [4] agreed with the present study and revealed that underlying factors such as age, work experience in nursing, nursing experience in critical care with clinical and professional competence level was a positive relationship with nurses' competence, moreover Salonenetal A., 2007 [23] found a positive and significant relationship between these factors and clinical competence level, while Meretoja R., et al. 2015 [17] agreed and found self-assessed competence increased with age.

\section{Conclusion}

The present study has been done to explore competency level of ICUs and CCUs nurses as well as to clarify influencing factors on clinical and professional competence by nurse's self-assessment of clinical and professional competence in knowledge, skill, attitude and value and experience. Results revealed that most of the studied nurses had excellent overall competency level with good competency level of knowledge, skill, attitude and value and experience base in addition that working units and number of years of experience in the current units was significant factors related to competency level. 


\section{Recommendations}

From the results of the present study, it can be recommended that:

1. Adding of more than one data collection method to avoid subjectivity of the assessment results.

2. Using of knowledge test and skill checklists and other objective method of evaluation together with the selfevaluation competency scale.

3. Further research with other hospital units and including of qualitative prospective would provide better results.

4. Comparative study of competency level of nurses in ICUs and other hospital units.

5. More emphasis should be given on basic skills and knowledge of intensive and critical care nursing in the educational setting.

\section{References}

[1] Afandi M (2014). Development of An Assessment Tool in Measuring Competencies of Head Nurse, The Malaysian Journal of Nursing; 5 (2) 27-34.

[2] Alfieri M, Marina M, Valentina B, Leopoldo (2017). Advanced competencies mapping of critical care nursing: a qualitative research in two Intensive Care Units, Acta Biomed for Health Professions; 88, S. 3: 67-74 DOI: 10.23750/abm. v88i3-S.6616.

[3] Aqtash S, Walter R, Lyndal Hunter A, Abeer H, Sharon B. (2017) Self-Assessed Competence of Experienced Expatriate Nurses in a Rural and Remote Setting. SAGE Open Nursing; 3: 1-17.

[4] Balneini M. Moattari K, Alnnadi F (2010). Self-assessment of the clinical competence of nurses in a major educational hospital of Shiraz University of Medical Sciences. J. Jahrom Univ. Med. Sci; 8: 28-36.

[5] Chamberlain D, Wendy P, Paul F. (2018). ACCCN Workforce Standards for Intensive Care Nursing: Systematic and evidence review, development, and appraisal. Australian Critical Care 31 (2018) 292e302.

[6] Dunn V, Lawson D, Robertson S, Underwood M, Clark R, Valentine T, et al. (2000). The development of competency standards for specialist critical care nurses. J Adv Nurs; 31 (2): 339-46. doi: 10.1046/j.1365-2648.2000.01292. x. PubMed. Cross Ref. Google Scholar.

[7] European Federation of Critical Care Nursing Association. Ef CCNa Competencies for European Critical Care Nurses.2013. http://www.efccna.org/images/stories/publication/competencie s_cc.pdf.Google Scholar.

[8] Ghahrisarabi A, Ali S, Sima N, Maryam R. (2016). Clinical and Professional Competence of Practicing Nurses in Intensive and Critical Care Units, Research Journal of Medical Sciences; 10 (4): 406-411.

[9] Intensive care units (ICUs). Retrieved 2018 from. http://healthywa.wa.gov.au/Articles/F_I/Intensive-care-unitsICUs

[10] Irimia R, Gottschling M. (2016). Taxonomic revision of Rochefortia Sw. (Ehretiaceae, Boraginales). Biodiversity Data Journal 4: e7720. https://doi.org/10.3897/BDJ.4.e7720.
[11] Jafari Z. Vanakiand R. (2008). Organizing nursing mentors committee: An effective strategy for improving novice nurses' clinical competency. Iran. J. Med. Educ; 7: 237-246.

[12] Karirnyar M. (2013). Nurses quality of performance in intensive care units based on synergy model. Iran J. Nurse. 26: 74-83.

[13] Lakanmaa R, Suominen T, Perttilä J, Puukka P, Leino-Kilpi H. (2012). Competence requirements in intensive and critical care nursing still in need of definition? A Delphi studies. Intensive and Critical Care Nursing; 28 (6): 329-336. doi: 10.1016/j.iccn.2012.03.002. PubMed, CrossRef, Google Scholar.

[14] Lakanmaa R, Suominen T, Perttila J, Ritmala-Castrén M, Vahlber T, \& Leino - Kilpi, H. (2013). Basic competence in intensive and critical care nursing: development and psychometric testing of a competence scale. Retrieved January 30,2018 , from http://onlinelibrary.wiley.com/doi/10.1111/jocn.12057/abstract

[15] Lakanmaa R, Suominen, T, Ritmala-Castrén M, Vahlberg T, \& Leino-Kilpi, H. (2015). Basic Competence of Intensive Care Unit Nurses: Cross-Sectional Survey Study. Retrieved January 30, 2018, from https://www.hindawi.com/journals/bmri/2015/536724.

[16] Meretoja R, Leino-Kilpi H, Kaira M. (2004). Comparison of nurse competence in different hospital work environments. J Nurs Manag.; 12 (5): 329-36. doi: 10.1111/j.13652834.2004.00422. x. PubMed. Cross Ref.

[17] Meretoja R, Numminen O, Isoaho, H, \& Leino-Kilpi, H. (2015). Nurse competence between three generational nurse cohorts: A cross-sectional study. International Journal of Nursing Practice; 21, 350-358. doi: 10.1111/ijn.12297.

[18] Mika F. (2018). Nursing Competency: Definition, Structure and Development, Yonago Acta Med; 61 (1): 1-7. Published online. 2018 Mar 28. doi: 10.33160/yam.2018.03.001.

[19] Nobahar M. (2016). Competence of nurses in the intensive cardiac care unit. Electron Physician; 8 (5): 2395-2404. Published online. doi: 10.19082/2395.

[20] Nursing Explorer, Intensive Care Unit (ICU) Nurse Job Description. Retrieved (2018). from https://www.nursingexplorer.com/careers/intensive-care-unit-nurse.

[21] O'Leary J. Comparison of self-assessed competence and experience among critical care nurses. (2012). Journal of Nursing Management; 20 (5): 607-614. doi: 10.1111/j.13652834.2012.01394. x. Pub Med. Cross Ref. Google Scholar.

[22] Penoyer A. (2010). Nurse staffing and patient outcomes in critical care: a concise review. Critical Care Medicine; 38 (7): 1521-1528. doi: 10.1097/ccm.0b013e3181e47888. Pub Med. Cross Ref. Google Scholar.

[23] Salonen H, Kaunonen M, Meretoja R, Tarkka T. (2007). Competence profiles of recently registered nurses working in intensive and emergency settings. Journal of Nursing Management; 15 (8): 792-800. doi: 10.1111/j.13652934.2007.00768.x.Pub Med. Cross Ref. Google Scholar.

[24] South African Nursing Council. (2005). Competencies for Critical Care Nurse Specialist.

[25] Sunita L, Waraporn, Kantaporn. (2018). Lived experiences of intensive care nurses in caring for critically ill patients. British Association of Critical Care Nurses; 24 (1). 